\title{
Savoirs et fiction au Moyen Âge et à la Renaissance, sous la direction de Dominique BOUTET et Joëlle Ducos
}

\author{
Maria Colombo Timelli
}

\section{(2) OpenEdition}

\section{Journals}

Édition électronique

URL : https://journals.openedition.org/studifrancesi/12439

DOI : $10.4000 /$ studifrancesi. 12439

ISSN : 2427-5856

Éditeur

Rosenberg \& Sellier

\section{Édition imprimée}

Date de publication : 1 avril 2018

Pagination : 101-102

ISSN : 0039-2944

\section{Référence électronique}

Maria Colombo Timelli, «Savoirs et fiction au Moyen Âge et à la Renaissance, sous la direction de

Dominique воutet et Joëlle ducos », Studi Francesi [En ligne], 184 (LXII | I) | 2018, mis en ligne le 04 juillet 2018, consulté le 16 novembre 2021. URL : http://journals.openedition.org/studifrancesi/12439; DOI : https://doi.org/10.4000/studifrancesi.12439

Ce document a été généré automatiquement le 16 novembre 2021.

\section{(c) (i) (9)}

Studi Francesi è distribuita con Licenza Creative Commons Attribuzione - Non commerciale - Non opere derivate 4.0 Internazionale. 


\title{
Savoirs et fiction au Moyen Âge et à la Renaissance, sous la direction de Dominique BOUTET et Joëlle Ducos
}

\author{
Maria Colombo Timelli
}

\section{RÉFÉRENCE}

Savoirs et fiction au Moyen Âge et à la Renaissance, sous la direction de Dominique BOUTET et Joëlle Ducos, Paris, PUPS, 2015, 411 pp.

1 Le but de ce recueil, dont nous rendons compte aussi dans la section "Quattrocento», est d'essayer de répondre à la question, toujours d'actualité, du rapport entre littérature et promotion du savoir sur une longue durée, allant du Moyen Âge - qui voit la naissance tant de la littérature que des « encyclopédies» en langue vernaculaire - au $\mathrm{XVI}^{\mathrm{e}}$ siècle, où semble se situer une véritable rupture.

De nombreuses contributions portent sur la production médiévale.

3 Jean-René VALETTE (Fiction arthurienne et 'authenticité théologique': la 'Queste del Saint Graal', pp. 123-142) s'interroge sur le "savoir" impliqué dans la Queste (pour l'essentiel : patristique, liturgie, Bible), pour vérifier ensuite le système qui s'y instaure par lequel le Graal devient le signe romanesque de Dieu, et Galaad un alter Christus voire un miles Christi. La chevalerie s'affirme ainsi comme service rendu à Dieu.

Roman « historique», ou plutôt roman " géographique», l'Alexandre de Thomas de Kent (vers 1170) fait une large part à l'encyclopédisme du XII ${ }^{\mathrm{e}}$ siècle, tout en marquant une étape importante dans la christianisation de l'empereur des Macédoniens. Une profonde connaissance des sources de Thomas permet à Catherine GAULLIER-BOUGASSAS de reconnaître l'étendue de ses emprunts, mais aussi celle des fictions dues à l'auteur médiéval (Savoir scientifique et "roman historique»: le "Roman d'Alexandre" de Thomas de Kent, pp. 143-159). 
5 Après avoir passé en revue la bibliographie critique, Didier KAHN nie la présence de l'alchimie dans la littérature médiévale, et en particulier dans les œuvres qui lui ont été associées (le Conte du Graal de Chrétien, sa Seconde Continuation par Wauchier de Desnain, le Parzival de Wolfram von Eschenbach, le Tristan de Gottfried von Strasbourg ; et, un peu plus tard Perceforest, le Cueur d'amour espris de René d'Anjou, le roman de Fauvel). Par ailleurs, D.K. souligne bien que des interprétations alchimiques d'une partie de cette littérature furent avancées dès le $\mathrm{xvI}^{\mathrm{e}}$ siècle (Présence et absence de l'alchimie dans la littérature romanesque médiévale, pp. 161-186, avec des extraits en annexe).

6 À partir d'une double métaphore qui, dans le Lancelot en prose, oppose cuer de cire et cuer dur d'aïmant du chevalier, Joëlle Ducos parcourt de nombreux textes littéraires et scientifiques afin de dévoiler les sens concrets et symboliques de ces deux matériaux. Ambigus tant par leurs usages que par leur sens (le second terme pouvant indiquer tant l'aimant que le diamant), ils dévoilent indirectement, dans la citation du Lancelot mais non seulement, la compénétration du monde de la fiction et de celui des savoirs ("Cuer de cire", "cuer d'aïmant" : la matière comme métaphore, pp. 201-219).

7 La contribution de Francine MORA (Femmes savantes et réflexion sur les savoirs au XII siècle: la fiction romanesque au service de l'épistémologie, pp. 285-297) s'attache à montrer comment le renouveau des sciences et de leur classement - notamment pour la médecine - qui se met en place au XII ${ }^{e}$ siècle se reflète aussi dans les romans : Médée chez Benoît de Sainte-Maure, Thessala dans Cligés et Mélior dans Partonopeus, incarnent ce nouveau savoir et mettent en valeur la médecine de leur temps.

8 Sylvie Bazin-tacchella (Malades et maladies dans les "Miracles de Notre Dame par personnages", pp. 299-320) étudie la représentation de la lèpre et du lépreux dans quelques Miracles de Notre Dame ( $\mathrm{XIV}^{\mathrm{e}}$ siècle). Les occurrences des mots medicine / medicinable, garis / garison, malade (subst. et adj.) montrent que ce sont les manifestations les plus visibles de la maladie qui sont mises en scène, ainsi que les attitudes des proches et les remèdes, essentiellement hors-norme et miraculeux. Ce discours hérite évidemment en partie des sources des Miracles, mais est aussi le reflet des représentations contemporaines de la lèpre, voire des traités médicaux les mieux connus - entre autres, celui de Guy de Chauliac.

9 Associé souvent à la logorrhée et à l'incohérence, le discours de Nature, qui occupe quelque 2700 vers dans le Roman de la Rose, est analysé par Armand STRUBEL en relation avec le savoir de Jean de Meung, mais surtout avec la fiction qui l'entoure et avec l'interprétation que donne Genius de cet enseignement cosmique hiérarchisé allant de Dieu à l'homme (Le discours de Nature dans le "Roman de la Rose": une mise en scène des savoirs?, pp. 321-334).

10 Seconde partie du Livres du roy Modus et de la royne Ratio, le Songe de Pestilence (1373-1377) est un ouvrage allégorique qui se veut une condamnation des vices de son temps : s'avérant selon Jean-Patrice BOUDET «à la pointe de la réflexion doctrinale et juridique» sur la magie et la divination (p.343), il fait notamment l'apologie de l'astronomie-astrologie naturelle (Des savoirs en question sous le règne de Charles V: sorcellerie et astrologie dans le "Songe de Pestilence", pp. 335-346).

11 Jean-Marie FRITZ recherche dans le corpus des « encyclopédies» du XIII ${ }^{\mathrm{e}}$ siècle - Image du monde de Gossuin de Metz, Trésor de Brunet Latin, Placides et Timéo et Sidrac - le motif fictionnel de l'origine et de la transmission du savoir : il peut ainsi montrer comment les «encyclopédistes» s'efforcent de dépasser les ruptures bibliques (péché originel, 
déluge, Babel) par l'idée d'une translatio continue et sans solution de continuité (Mise en fiction de la transmission du savoir dans les encyclopédies françaises du XIII siècle, pp. 347-361).

12 Laurent-Henri VIGNAUD (Un héritage bien encombrant : la relecture des "Livres de merveilles" médiévaux par les savants de la Renaissance, pp. 73-95) suit la réception du 'merveilleux' médiéval au $\mathrm{XVI}^{\mathrm{e}}$ siècle, en rappelant les éditions de quelques œuvres représentatives : le Livre des Merveilles, publié jusqu'en 1534, ou les Etymologies d'Isidore, dont les éditions s'espacent au fil de ce siècle. En même temps, l'intérêt s'affirme pour les merveilles locales, du Dauphiné en l'occurrence, elles aussi d'origine médiévale (dérivées de Gervais de Tilbury), mais expurgées et revisitées. 